\title{
Reproduction in Schlieffen's bat, Nycticeius schlieffenii, in the eastern Transvaal lowveld, South Africa
}

\author{
M. van der Merwe and I. L. Rautenbach* \\ Mammal Research Institute, University of Pretoria, 0002 Pretoria, and \\ *Transvaal Museum, P.O. Box 413,0001 Pretoria, Republic of South Africa
}

\begin{abstract}
Summary. The present study is based on 153 Schlieffen's bats collected over a 2-year period from September 1983 to September 1985. Spermatogenesis extends over a 10-month period with the first signs of spermatozoa in the epididymides by the end of April. Spermatozoa were present in the epididymides from the end of April until the beginning of September. Copulation begins during June (early winter) and the females have spermatozoa in the uterine horns from then until the end of August (late winter) when ovulation occurs. These bats are seasonally monoestrous with the great majority of births occurring during November. The number of conceptuses varied; a maximum of 5 pre-implanted embryos was recorded, but the maximum number of fetuses observed was 3.
\end{abstract}

\section{Introduction}

Schlieffen's bat (Nycticeius schlieffenii) is one of the smallest bat species in the southern African subregion with males averaging $4 \cdot 7 \mathrm{~g}$ and females $5 \cdot 1 \mathrm{~g}$ (Rautenbach, 1982). It has an extensive range in south-western Arabia and in most of sub-Saharan Africa with a distinct easterly distribution in southern Africa, indicating a propensity for drier woodlands at lower altitudes. This species utilizes crevices and hollows in trees as daytime roosts (Verschuren, 1957) as well as rock crevices (Pienaar et al., 1980), houses, huts and cellars (Rosevear, 1965). Although it is common and widely distributed, virtually nothing is known about its life history. In the Pafuri region $\left(22^{\circ} 25^{\prime} \mathrm{S} ; 31^{\circ} 12^{\prime} \mathrm{E}\right)$ in the north of Kruger National Park, where this study was conducted, specimens were mist-netted throughout the year, suggesting that Schlieffen's bat does not hibernate or enter into deep torpor for prolonged periods during winter. The latter view is supported by its observed reproductive activities which are initiated at the onset of the southern hemisphere winter (June-August).

The climate at Pafuri is warm to very hot with a fairly high humidity. Average daily maximum temperatures are of the order of $30^{\circ} \mathrm{C}$ in January (extreme $43^{\circ} \mathrm{C}$ ) and $23^{\circ} \mathrm{C}$ in July (extreme $35^{\circ} \mathrm{C}$ ) with a mean annual (predominantly summer) precipitation of $438 \mathrm{~mm}$ (Gertenbach, 1983).

The purpose of the present study was to examine the reproductive biology of Schlieffen's bat in northern Kruger National Park.

\section{Materials and Methods}

Specimens were collected during the last week of each month, the aim being to acquire 10 bats for each calendar month (with emphasis on females). Altogether, 153 specimens ( 56 males; 97 females) were collected between September 1983 and September 1985.

The bats were procured with two $100 \times 20$ foot mist-nets (Rautenbach, 1985). Dates of collection and sample sizes are given in Table 1. At the field laboratory the bats were killed with chloroform and the reproductive tracts dissected out and preserved. Testes and epididymides, non-pregnant uteri and uteri containing small embryos were stored in Bouin's fluid. Uteri containing fetuses were stored in AFA (a mixture of $95 \%$ ethyl alcohol, $40 \%$ formalin, glacial acetic acid and distilled water, in the ratio of $3: 1: 1: 5$, by vol.). When fetuses were macroscopically discernible their 
numbers and distribution in the two uterine horns were recorded. Following routine paraffin wax embedding, all the ovaries and uteri of non-pregnant females as well as those with embryos or small fetuses were serially sectioned at $8 \mu \mathrm{m}$ and the mounted series were stained with Ehrlich's haematoxylin and eosin. For uteri containing large fetuses, only the ovaries were serially sectioned at $8 \mu \mathrm{m}$ and thereafter prepared as above. Testes and epididymides were sectioned at $8 \mu \mathrm{m}$ and prepared for microscopical examination similar to the female material.

\section{Results}

\section{Spermatogenesis}

Spermatogenic activity was found to extend over a 10 -month period. The first signs of spermatogenesis were observed during late September when mitotic divisions could be found in some of the spermatogonia present. From then onwards increased mitotic activity resulted in increased numbers of spermatogonia. Primary spermatocytes became abundant towards the end of February. First meiotic divisions became conspicuous from late March onwards when secondary spermatocytes became obvious.

Second meiotic divisions followed shortly after the first meiotic divisions as spermatids and the first signs of spermatozoa became apparent in the seminiferous tubules of males collected in late March (Fig. 1). Spermatozoa appeared in the epididymides during the last week of April. During May, June and July the epididymides were filled with spermatozoa. During the last week of July the epididymides were still filled with spermatozoa, and although large numbers of spermatozoa could still be found in many of the seminiferous tubules, spermatogenic activity had ceased (Fig. 2). Other seminiferous tubules were lined only with Sertoli cells and a few inactive spermatogonia but there were no spermatozoa attached to the Sertoli cells. Males collected in August had spermatozoa remaining in their epididymides but no trace of spermatozoa could be found in the seminiferous tubules (Fig. 3). Spermatozoa were therefore present and available for 2.5-3 months (late June to early September) after the onset of the mating season.

Copulation in this species began during June, probably the second half of the month. From then onwards masses of spermatozoa were present in the uterine horns of the females until the end

Table 1. The sizes and reproductive conditions of respective monthly samples of Schlieffen's bat

\begin{tabular}{|c|c|c|c|}
\hline Date & No. males & No. females & Reproductive status of females \\
\hline $25-30$ Sept. 83 & 5 & 5 & $\begin{array}{l}5 \text { Pregnant with embryos from morulae to implanting bilaminar } \\
\text { blastocysts }\end{array}$ \\
\hline $25-30$ Oct. 83 & 5 & 5 & 5 Pregnant with fetuses at limb-bud stage \\
\hline $25-30$ Nov. 83 & 5 & 6 & 1 Pregnant with near-term fetuses (mean mass $0.90 \mathrm{~g}$ ); 5 lactating \\
\hline 25-30 Dec. 83 & 5 & 4 & All non-pregnant \\
\hline 25-30 Jan. 84 & 4 & 7 & All non-pregnant \\
\hline 24-28 Febr. 84 & 3 & 6 & All non-pregnant \\
\hline $25-30$ March 84 & 4 & 6 & All non-pregnant \\
\hline 25-30 April 84 & 3 & 7 & All non-pregnant \\
\hline $25-30$ May 84 & 3 & 7 & All non-pregnant \\
\hline $25-30$ June 84 & 6 & 5 & All non-pregnant; spermatozoa in uterine horns \\
\hline $25-30$ July 84 & 1 & 3 & All non-pregnant; spermatozoa in uterine horns \\
\hline $25-30$ Aug. 84 & 3 & 5 & $\begin{array}{l}4 \text { Pregnant with embryos from oocytes to morulae; } 1 \text { with large } \\
\text { Graafian follicles }\end{array}$ \\
\hline $24-30$ Sept. 84 & 1 & 7 & 7 Pregnant with embryos from morulae to primitive streak stages \\
\hline $25-30$ Oct. 84 & 3 & 5 & 5 Pregnant with fetuses with recognizable limbs and patagium \\
\hline $25-30$ Nov. 84 & 5 & 5 & All lactating \\
\hline $24-30$ Aug. 85 & - & 11 & $\begin{array}{l}5 \text { Pregnant with embryos from zygotes to implanting bilaminar } \\
\text { blastocyst stages; } 6 \text { with medium to mature Graafian follicles }\end{array}$ \\
\hline 4 Sept. 85 & - & 3 & $\begin{array}{l}3 \text { Pregnant with embryos from morulae to implanting bilaminar } \\
\text { blastocyst stages }\end{array}$ \\
\hline
\end{tabular}




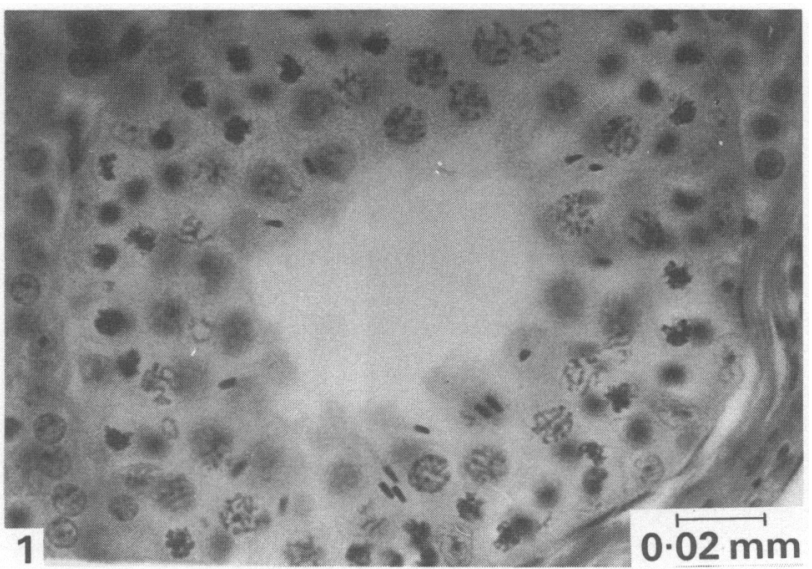

Fig. 1. Section through a testis of a Schlieffen's bat showing a seminiferous tubule with many primary spermatocytes and some spermatozoa.

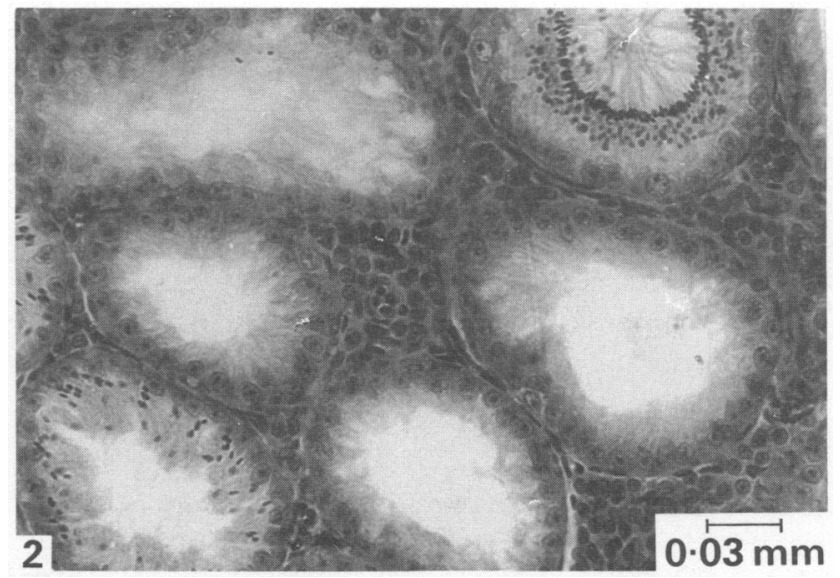

Fig. 2. Section through the testis of a Schlieffen's bat during the last week of July showing some seminiferous tubules with spermatozoa while others contained primarily Sertoli cells and occasional spermatogonia.

of August when ovulations started. Seven females collected in late May 1984 revealed no trace of spermatozoa in the genital tracts while all 5 females collected in late June had sperm masses in the uterine horns (Table 1; Fig. 4).

Spermatozoa directly adjacent to the endometrium were orientated parallel to each other with their heads towards the columnar epithelium of the uterine horns (Fig. 4).

\section{Ovulation}

Ovulation is expected to occur from about the last half of August to the last half of September. The biggest embryos observed at the earliest date were morulae on 30 August 1984 and implanting blastocyts on 30 August 1985 (Table 1; Fig. 5). These embryos therefore must have resulted from fertilizations that occurred during the second half of August. The youngest embryos collected on the latest dates during the present study were morulae on 30 September 1983 and 24 September 


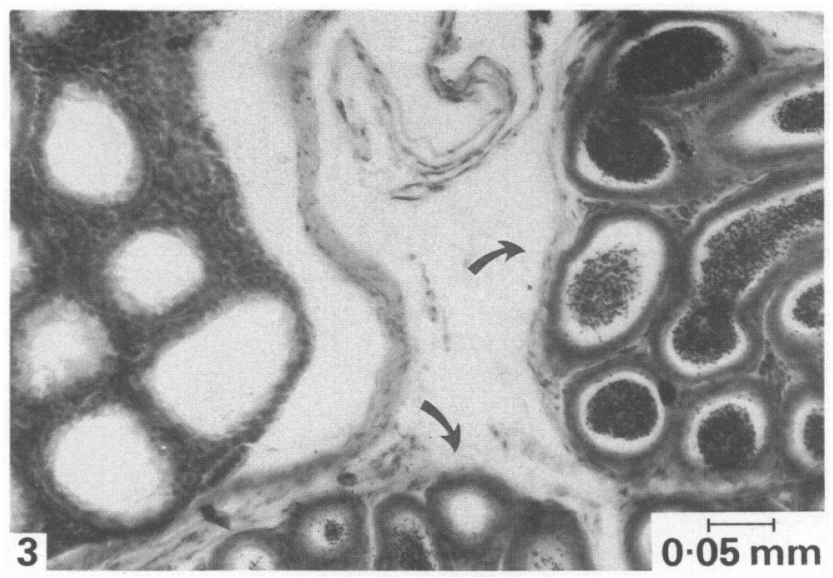

Fig. 3. Section through part of the testis and epididymidis of a Schlieffen's bat during the last week of August showing the presence of spermatozoa in the cauda epididymidis (indicated with arrows) while the seminiferous tubules only contain Sertoli cells and occasional spermatogonia.

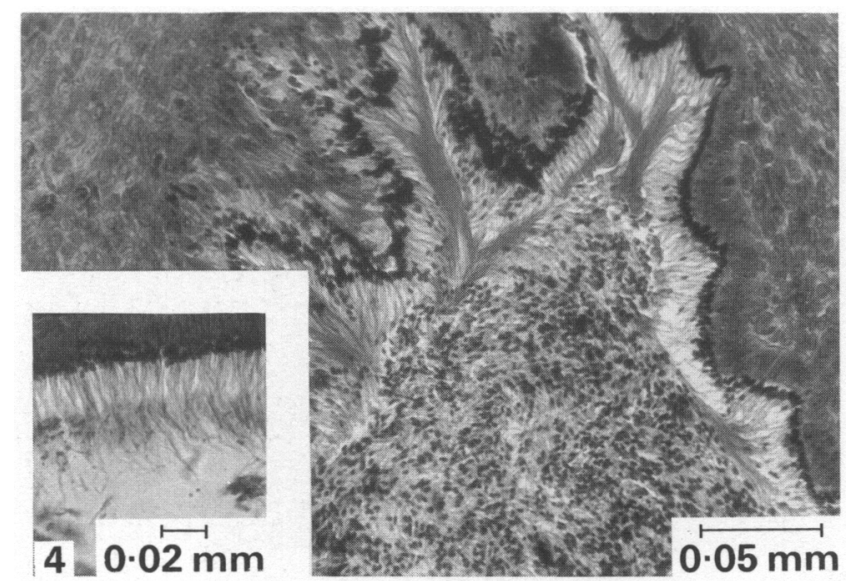

Fig. 4. Section through the utero-tubal junction region of a uterine horn of Schlieffen's bat collected in June showing masses of spermatozoa orientated towards the epithelium and masses of spermatozoa filling the uterine lumen. Inset showing part of one of the uterine horns with spermatozoa hanging parallel to each other with their heads orientated towards the uterine epithelium.

1984 (Table 1; Fig. 6). These embryos would then represent the last fertilizations of the season, i.e. during the second part of September. All females collected in October were carrying fetuses of various sizes and ages and no female with unimplanted embryos or mature Graafian follicles was found (Table 1).

\section{Fertilization}

Mature Graafian follicles were infrequently found as the majority of females collected during the breeding season were post-ovulatory (already pregnant). Of 11 females collected during the last week of August 1985, however, 4 had mature Graafian follicles (Fig. 7). In 2 of these females 


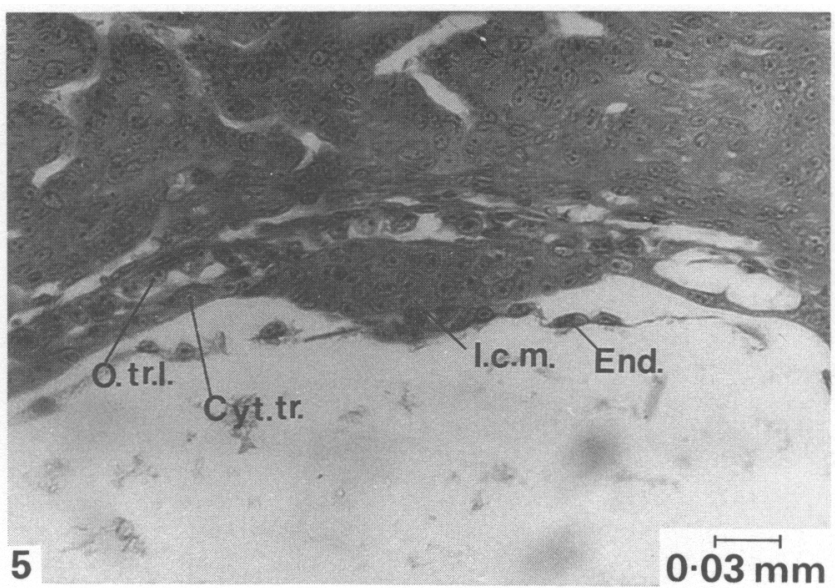

Fig. 5. Section through part of a uterine horn of Schlieffen's bat showing an embryo implanting. The inner cell mass (I.c.m.), endoderm (End.), cytotrophoblast (Cyt. tr.) and overlying trophoblast layer (O.tr.l.) are clearly visible.

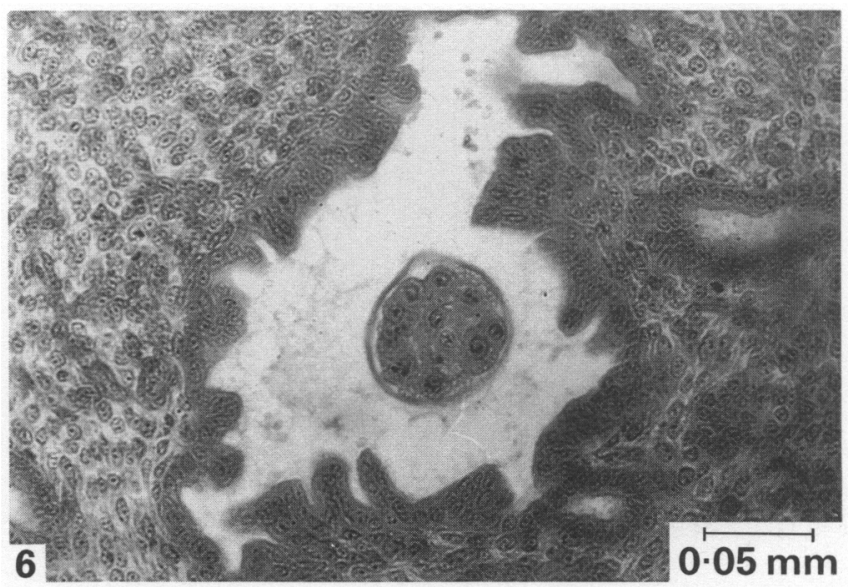

Fig. 6. Morula in the lumen of the right uterine horn of Schlieffen's bat.

spermatozoa were located in the distal parts of the oviducts. A few spermatozoa were scattered through the lumina of the uterine horns. However, while large numbers of spermatozoa were still present in the utero-tubal junction area with their heads orientated towards the epithelium, others were mixed with debris in the lumen (Fig. 8). In the remaining 2 females with mature Graafian follicles, a few spermatozoa were found amongst debris in the utero-tubal junction area and none elsewhere in the oviducts. Nearly all spermatozoa had disappeared from the genital tract shortly after fertilization. No spermatozoa could be found in the oviducts of any of the females with zygotes or small embryos, while isolated groups of spermatozoa were found in some of the utero-tubal junctional areas.

\section{Litter size}

Schlieffen's bats were considered to be monoestrous, giving birth seasonally to litters of various sizes. The number of conceptuses found in 34 pregnant females, their distribution between the right and left uterine horns as well as the number and distribution of the corpora lutea are given in Table 2. 


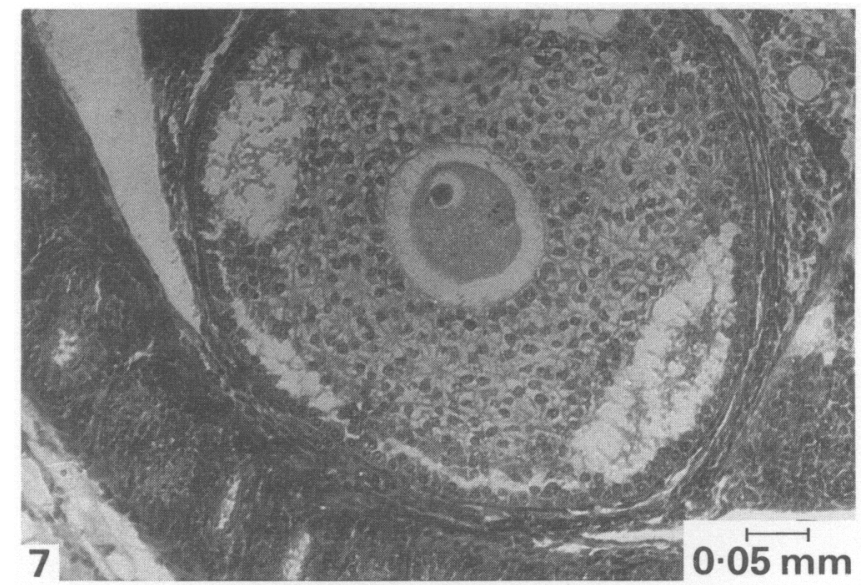

Fig. 7. Mature Graafian follicle in the right ovary of Schlieffen's bat.

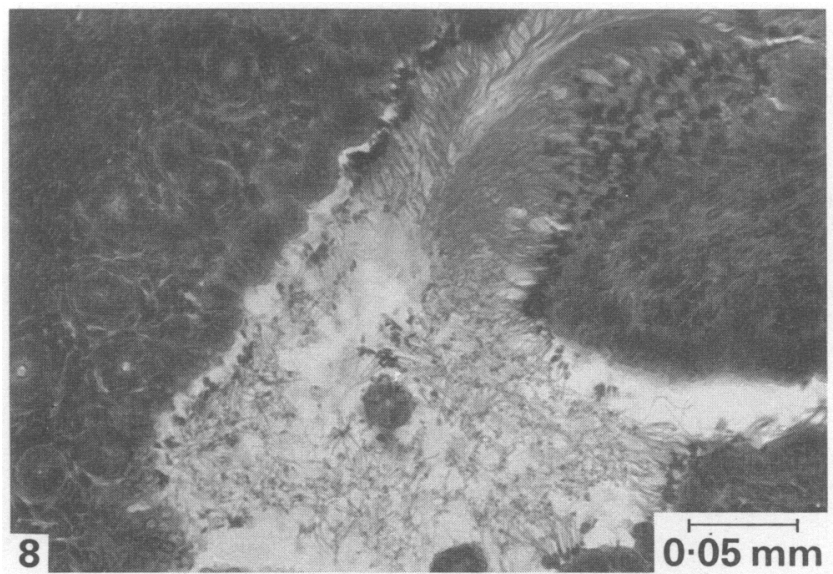

Fig. 8. Section through the utero-tubal junction area of Schlieffen's bat showing spermatozoa orientated towards parts of the epithelium while others in the lumen are mixed with debris.

Of 31 pregnant females ( $19 \%$ ) for which both ovaries were examined, 6 had more corpora lutea than conceptuses indicating resorption, while $5(16 \%)$ had more conceptuses than corpora lutea which could indicate possible monozygotic twins (Table 2 ). In most females examined (65\%) more corpora lutea were found in the right ovary than in the left ovary. In the females carrying twins and triplets, the sum total of corpora lutea in their right ovaries was approximately double the sum total of those in their left ovaries (Table 2). In most females the left ovary had one or no corpora lutea, while the right ovary had I-3 (Table 2). The maximum number of corpora lutea found in the left ovary was two $(\mathrm{N}=5$ ) (Table 2). In a single female, more corpora lutea were found in the left ovary (2) than in the right ovary (1) (Table 2).

In the 2 females with quadruplets for which the ovaries were examined, a total of 5 corpora lutea was counted in the right ovaries compared to 3 in the left ovaries. The females carrying a single conceptus had a single corpus luteum in each ovary, while the female carrying 5 conceptuses had 2 corpora lutea in each ovary (Table 2 ). 
Table 2. The distribution of conceptuses between the uterine horns and the number and distribution of the corpora lutea between the ovaries in Schlieffen's bat

\begin{tabular}{|c|c|c|c|c|}
\hline $\begin{array}{l}\text { Right } \\
\text { uterine } \\
\text { horn }\end{array}$ & $\begin{array}{c}\text { Left } \\
\text { uterine } \\
\text { horn }\end{array}$ & $\begin{array}{l}\text { Right } \\
\text { ovary }\end{array}$ & $\begin{array}{l}\text { Left } \\
\text { ovary }\end{array}$ & $\begin{array}{l}\text { Conceptus } \\
\text { status }\end{array}$ \\
\hline \multicolumn{5}{|c|}{ Single (I litter) } \\
\hline$+^{*}$ & * & + & + & Fetus \\
\hline 1 & & 1 & 1 & \\
\hline \multicolumn{5}{|c|}{ Twins (10 litters) } \\
\hline+ & + & + & - & Fetus \\
\hline+ & + & ++ & + & Primitive streak stage \\
\hline+ & + & ++ & + & Blastocyst \\
\hline+ & + & ++ & + & Fetus \\
\hline+ & + & ++ & - & Fetus \\
\hline+ & + & ++ & ++ & Fetus \\
\hline+ & + & + & + & Fetus \\
\hline+ & + & ++ & + & Implanting: bilaminar blastocyst \\
\hline+ & + & + & + & Implanting: blastodisc stage \\
\hline+ & + & + & + & Implanting: blastodisc stage \\
\hline 10 & 10 & 16 & 9 & \\
\hline \multicolumn{5}{|c|}{ Triplets (18 litters) } \\
\hline++ & + & $++t$ & - & Morula \\
\hline++ & + & ++ & + & Fetus \\
\hline++ & + & ++ & + & Fetus \\
\hline++ & + & ++ & + & Fetus \\
\hline++ & + & + & + & Fetus \\
\hline++ & + & $\dagger$ & $\dagger$ & Fetus \\
\hline+++ & - & $+t+$ & - & Zygote \\
\hline++ & + & ++ & + & Morula \\
\hline++ & + & ++ & + & Zygote \\
\hline+ & ++ & ++ & + & Morula \\
\hline++ & + & + & ++ & Blastocyst \\
\hline++ & + & + & + & Implanting: bilaminar blastocyst \\
\hline++ & + & ++ & ++ & Implanting: bilaminar blastocyst \\
\hline++ & + & $+t+$ & - & Morula \\
\hline++ & + & ++ & + & Zygote \\
\hline++ & + & ++ & + & 2-4-cell stage \\
\hline++ & + & ++ & + & 2-4-cell stage \\
\hline++ & + & ++ & + & Morula \\
\hline 36 & 18 & 34 & 16 & \\
\hline \multicolumn{5}{|c|}{ Quadruplets (4 litters) } \\
\hline++ & ++ & + & $\dagger$ & Primitive streak stage \\
\hline++ & ++ & $\dagger$ & $\dagger$ & Morula \\
\hline++ & ++ & ++ & ++ & Morula \\
\hline$++t$ & + & +++ & + & Oocyte \\
\hline 9 & 7 & 5 & 3 & \\
\hline \multicolumn{5}{|c|}{ Quintuplets (1 litter) } \\
\hline+++ & ++ & ++ & ++ & Morula \\
\hline 3 & 2 & 2 & 2 & \\
\hline
\end{tabular}

*Atrophied conceptuses.

†Ovaries not examined. 
The median number of conceptuses in utero was 3 as $53 \%$ of the pregnant females were carrying 3 conceptuses, followed by $29 \%$ carrying twins but final litter size would probably be less because of embryo loss. Nevertheless, embryo loss probably had its greatest effect on pre-implanted embryos as only one female was obtained in which implanted conceptuses were observed undergoing resorption. This female had 1 fetus in the right uterine horn (Table 2) as well as an atrophied conceptus in each of the horns. In most females with triplets, 2 conceptuses were located in the right uterine horn and one in the left (Table 2). In some of these females this specific arrangement was made possible due to transuterine migrations. This was especially obvious where all the corpora lutea were in one ovary with conceptuses in both uterine horns (Table 2).

\section{Gestation}

The majority of births occurred during November. All females collected during the last week of October, both in 1983 and 1984, carried 1-3 fetuses. Virtually all females collected during the last week of November in both seasons were lactating, but a single female collected on 30 November 1983 was carrying near-term fetuses (Table 1). These fetuses should have been born within the first half of December. Therefore, with ovulations expected from the last half of August to the end of September (see above) and births from the beginning of November to about mid-December, the gestation period was estimated to be approximately 11 weeks.

\section{Discussion}

The majority of bat species are monotocous with one oestrous cycle per annum (Wimsatt, 1975; Hill \& Smith, 1984). A similar trend is evident for the majority of Southern Africa bats for which information is available (Rautenbach, 1982; Smithers, 1971, 1983). Although twins are common in some bat species in the southern African subregion, triplets have only been documented as exceptional cases in one female each of the Cape serotine bat (Eptesicus capensis) and the yellow house-bat (Scotophilus dinganii) by Rautenbach (1982). Litters of more than 3 have rarely been recorded for bats, one example being the occasional instances of 4 (Lyon, 1903) and rare instances of 5 young (Mumford, 1973) of the red bat, Lasiurus borealis.

In Schlieffen's bat the highest number of preimplantation embryos found was 5 morulae (Table 2). This high number is regarded as exceptional since it was found in one instance only during the present study. Only one of the females with quadruplets had implanted embryos at the primitive streak stage (Van der Merwe \& Rautenbach, 1986). Whether all 4 (or more) fetuses are carried to term is uncertain as all females collected with fetuses (i.e. with visible limb-buds and bigger) invariably had a maximum of 3 per female.

Although the present study revealed a potential litter size of $3(53 \%)$ or $2(29 \%)$ (Table 2$)$ it is expected that fewer triplets and therefore more twins will eventually be born because it is expected that some embryo loss, especially among the females carrying triplets, would have occurred. This assumption is based on the fact that nearly $50 \%$ of the females carrying twins started off with potential triplets as indicated by the number of corpora lutea (Table 2). In the case of those females bearing twins, 4 had 3 corpora lutea and 1 had 4 corpora lutea, indicating that embryo loss had curtailed potential litters of 3 and 4 . Amongst the females with triplets, 1 had 4 corpora lutea, also indicating embryo loss (Table 2). This study therefore suggests that embryo loss has a significant effect on litter size. However, there is the possibility that when the number of corpora lutea exceeds the number of conceptuses, it may in at least some individuals be the result of accessory corpora lutea formed from unruptured follicles. We were, however, unable to find remnants of oocytes in any of the corpora lutea.

Ovum loss is not uncommon amongst bats. Wimsatt (1945) has found that the eastern pipistrelle (Pipistrellus subflavus) normally bears 2 young, and that the big brown bat (Eptesicus fuscus) bears 
1 or 2, but that in both 2-7 ova are normally shed. Most of these implant but those in excess of the number of young characteristically produced are eventually resorbed. In the vespertilionid Eptesicus furinalis there is an increasing loss of embryos as gestation proceeds, with an average of 1.9 embryos and 3.5 corpora lutea by late pregnancy and with most of the embryos being lost after implantation (Myers, 1977).

With the exception of two females, post-implantation triplets were always (89\%) distributed 2 in the right and 1 in the left uterine horn (Table 2). In the two exceptions (Table 2), it is possible that the embryos had not yet reached their final destination for implantation and that transmigration between the uterine horns might still have occurred. It is clear that singletons will not be common in this species based on only one of the pregnant females collected with a single fetus, but which also had an atrophied conceptus in each uterine horn.

Because examination of the ovaries of non-pregnant females has revealed no obvious signs of polyovular follicles, it is believed that monozygotic twins may readily appear in this species. We may, on the other hand, have failed to recognize the division between two corpora lutea that were tightly pressed together, although such a possibility is doubtful.

Sperm storage by either sex has been reported for members of the families Rhinolophidae and Vespertilionidae (Racey, 1979). In male bats the cauda epididymidis and ductus deferens act as sperm stores with the testes being a possibility in the Canyon bat, Pipistrellus hesperus (Racey, 1979). In females of the various species there appear to be three main locations where spermatozoa are stored: the uterus, the utero-tubal junction and the oviduct. In Schlieffen's bat there are strong indications that spermatozoa are stored in the female reproductive tract because copulation starts 2-2.5 months before ovulation and fertilization during late winter and early spring. However, because females were not isolated from males after the first copulations, the possibility remains that spermatozoa from early copulations may be lost and replaced at subsequent matings, especially as the males have spermatozoa in their epididymides for about 5 months of the year (last half of April to the first half of September), overlapping with the time that the females have spermatozoa in their uteri (June to August). A similar situation has been described for Paraguayan vespertilionids (22-25 $\mathrm{S}$ ) where 3 of the 4 species studied copulate 1-3 months before they become pregnant during spring (Myers, 1977). In the males of these species spermatozoa can be found in the epididymides until conception has occurred (Myers, 1977), thus rendering winter copulations a possibility. Although Paraguayan bats do not hibernate, daily torpor is considered important by Myers (1977) during cool seasons. A similar situation is anticipated for Schlieffen's bats in the subtropical climate of the Pafuri region. The species studied by Myers (1977) give birth during the southern spring (September-November), while births in Schlieffen's bats occur mainly during November.

In temperate zones vespertilionid bats generally copulate during autumn and spermatozoa are then stored in the uterus of the females until the following spring when ovulation and fertilization occur (Racey \& Potts, 1970). However, in the subtropical climate of the Pafuri region, copulation in Schlieffen's bats is initiated after the onset of the South African winter (June) with the first ovulations towards the end of the winter (August), thus to a large extent being similar to Kitchener's (1975) findings on Gould's wattled bat, Chalinolobus gouldii, in Western Australia, females of which are also inseminated at the beginning of the winter, with ovulations towards the end of the winter. However, according to Kitchener (1975) Gould's wattled bats like other temperate-zone vespertilionids, appear to store spermatozoa. As this phenomenon has not yet been confirmed in Schlieffen's bat, it must be assumed at present that the continuous presence of spermatozoa in the uterine horns of females for a 2-2.5-month period before ovulation may in part be due to repeated copulations over that period.

We thank the Warden of the Kruger National Park, Dr U. de V. Pienaar, and Dr V. de Vos (Assistant Head: Research), for permission to conduct our research within the Park, and to use facilities at Pafuri; Dr L. E. O. Braack (Department of Research and Information of the National Parks Board) and Mr L. Hare (Pafuri ranger) for help in various ways during fieldwork operations; 
Mr D. Coetzer, Mr D. A. Wolhuter and Mr S. Ranthakwe for help with the collection and preservation of material. This project was financed by a CSIR Foundation for Research Development grant-in-aid to I.L.R. and by the Group Chairman's Fund of the Anglo-American and de Beer's Corporation, whereas laboratory running expenses were defrayed by a grant from the University of Pretoria.

\section{References}

Gertenbach, W.P.D. (1983) Landscapes of the Kruger National Park. Koedoe 26, 9-121.

Hill, J.E. \& Smith, J.D. (1984) Bats: a Natural History. University of Texas Press, Austin.

Kitchener, D.J. (1975) Reproduction in female Gould's Wattled Bat Chalinolobus gouldii (Gray) (Vespertilionidae) in Western Australia. Aust. J. Zool. 23, 29-42.

Lyon, M.W. (1903) Observations on the number of young of the Lasiurine bats. Proc. U.S. Nat. Mus. 26, 425. 426.

Mumford, R.E. (1973) Natural history of the red bat (Lasiurus borealis) in Indiana. Period. biol. 75, 155-158.

Myers, P. (1977) Patterns of Reproduction of Four Species of Vespertilionid Bats in Paraguay. University of California Press, Berkeley.

Pienaar, U. de V., Rautenbach, I.L. \& de Graaff, G. (1980) The Small Mammals of the Kruger National Park. National Parks of South Africa, Pretoria.

Racey, P.A. (1979) The prolonged storage and survival of spermatozoa in Chiroptera. J. Reprod. Fert. 56, $391-402$.

Racey, P.A. \& Potts, D.M. (1970) Relationship between stored spermatozoa and the uterine epithelium in the pipistrellus bat (Pipistrellus pipistrellus). J. Reprod. Fert. 22, 57-63.
Rautenbach, I.L. (1982) Mammals of the Transvaal. Ecoplan Monograph No. 1, Pretoria.

Rautenbach, I.L. (1985) A new technique for the efficient use of macro-mistnets. Koedoe 28, 81-86.

Rosevear, D.R. (1965) The Bats of West Africa. Trustees of the British Museum (Natural History), London.

Smithers, R.H.N. (1971) The mammals of Botswana. Mus. Mem. Natl. Mus. Monum. Rhod. 4, 1-340.

Smithers, R.H.N. (1983) The Mammals of the Southern African Subregion. University of Pretoria, Pretoria.

Van der Merwe, M. \& Rautenbach, I.L. (1986) Multiple births in Schlieffen's bat, Nycticeius schlieffenii from the southern African subregion. S. Afr. J. Zool. 21, 48-50.

Verschuren, J. (1957) Exploration du Parc National de la Garamba, 7, Chiropteres. Institute des Parcs Nationeaux du Congo Belge, Bruxelles.

Wimsatt, W.A. (1945) Notes on breeding behavior, pregnancy, and parturition in some vespertilionid bats in the eastern United States. J. Mammal. 26, 23-33.

Wimsatt, W.A. (1975) Some comparative aspects of implantation. Biol. Reprod. 12, 1-40.

Received 26 November 1986 